\title{
PENYULUHAN DAN PEMBERDAYAAN MASYARAKAT DALAM MEMPERKENALKAN BUDIDAYA TANAMAN SAYURAN DENGAN SISTEM HIDROPONIK
}

\author{
Ardiwijaya $^{[1]}$, Jeri Fernando ${ }^{[2]}$, Willia Cahaya Dita $^{[3]}$, Zalia Aprianti ${ }^{[4]}$, Anes \\ Meyzera $^{[5]}$, Aldi Gustomi ${ }^{[6]}$ \\ ${ }^{123456)}$ Program Studi Teknik Informatika, Fakultas Teknik, Universitas Muhammadiyah Bengkulu \\ Coresponden Author : ardiwijaya@umb.ac.id
}

Informasi Artikel

Terima: 06/01/2020

Revisi : 02/04/2021

Disetujui : 30/04/2021

\section{Kata Kunci :}

Hidroponik, Ntf, Desa

Taba Padang Rejang

\section{ABSTRAK}

Kegiatan pengabdian kepada masyarakat ini bertujuan untuk meningkatkan kemampuan masyarakat dalam mengembangkan budidaya tanaman sayuran dengan sistem hidroponik sehingga menghasilkan sayuran yang sehat, meningkatkan perekonomian dalam kebutuhan sehari-hari dan sebagai temat wisata di desa tersebut. Berdasarkan survey dan analisis situasi yang telah dilakukan maka dapat diidentifikasi permasalahan sebagai berikut: 1) Rendahnya pengetahuan tentang teknik budidaya sayur sederhana dengan menggunakan sistem hidroponik modern, 2) Belum ada sosialisasi tentang teknik budidaya sayur secara hidroponik 3) Masih kurangnya pemahaman masyarakat tentang pemanfaatan lahan sempit yang dapat dijadikan lahan sayur hidroponik modern dan 4) untuk memaksimalkan potensi-potensi yang dimiliki oleh suatu desa guna meningkatkan kesejahteraan masyarakatnya. Solusi yang ditawarkan kepada masyarakat adalah berupa informasi pemahaman berupa sosialisasi Panduan Hidroponik, Pemberdayaan Masyarakat melalui pertanian hidroponik pada desa taba padang rejang kecamatan hulu palik kabupaten bengkulu utara. Serta dilaksanakannya sosialisasi dalam pembuatan tanaman berbasis pertanian hidroponik. Oleh sebab itu, perlu adanya peningkatan peran masyarakat yang lebih baik terkait dengan pengembangan kegiatan pertanian hidroponik pada desa taba padang rejang kecamatan hulu palik kabupaten bengkulu utara. Adapun hasil dari pengabdian ini adalah warga memahami cara bertanam hidroponik serta mampu mempraktekkannya. Hasil dari program ini terbentuk desa percontohan hidroponik, pusat edukasi hidroponik, agromart dan menjadi desa agrowisata sesuai dengan program yang dicanangkan Kepala Desa taba padang rejang kecamatan hulu palik kabupaten bengkulu utara.

\section{PENDAHULUAN}

Penyuluhan dan Pemberdayaan masyarakat desa merupakan upaya untuk mengembangkan kemandirian dan kesejahteraan masyarakat dengan meningkatkan pengetahuan, sikap, 
keterampilan, perilaku, kemampuan, kesadaran, serta memanfaatkan sumber daya melalui penetapan kebijakan, program, kegiatan, dan pendampingan yang sesuai dengan esensi masalah dan prioritas kebutuhan masyarakat desa taba padang rejang kecamatan hulu palik kabupaten bengkulu utara.

Penyuluhan dan Pemberdayaan masyarakat desa bertujuan untuk membangun desa dalam melakukan sosialisasi bersama sebagai suatu kesatuan yang melibatkan berbagai kalangan kepentingan ditingkat pemerintah desa, masyarakat desa, maupun pihak lain untuk mendorong partisipasi dan mendayagunakan kemampuan masyarakat desa dalam proses pembangunan desa, menyusun perencanaan pembangunan yang berpihak pada kelompok miskin, serta meningkatkan kapasitas dan kualitas sumberdaya manusia di desa taba padang rejang kecamatan hulu palik kabupaten bengkulu utara.

Salah satu program pemberdayaan masyarakat yang dilaksanakan pada pengabdian kepada masyarakat ini adalah melalui kegiatan Hidroponik Sayuran modern. Untuk mencapai kondisi masyarakat yang hidup sehat dan sejahtera di masa yang akan datang dan dapat memanfaatkan ilmu teknologi pada masa modern saat ini untuk mengolah serta memanfaatkan lahan yang ada menjadi suatu penghasilan, maka hidroponik merupakan pilihan yang tepat.

Sistem hidroponik dapat memberikan suatu lingkungan pertumbuhan yang lebih terkontrol. Dengan pengembangan teknologi, kombinasi sistem hidroponik dengan membran mampu mendayagunakan air dan nutrisi secara nyata lebih efisien (minimalis system) dibandingkan dengan kultur tanah (terutama untuk tanaman berumur pendek). Penggunaan sistem hidroponik tidak mengenal musim dan tidak memerlukan lahan yang luas dibandingkan dengan kultur tanah untuk menghasilkan satuan produktivitas yang sama [1].

Salah satu system pertanian masa depan adalah hidroponik, karena dapat diusahakan diberbagai tempat, baik di desa, di perkotaan, di lahan terbuka, atau diatas apartemen. Luas tanah yang sempit, kondisi tanah keritis, hama dan penyakit yang terkendali, keterbatasan jumlah air irigasi, musim yang tidak menentu, dan mutu yang tidak seragam bisa ditanggulangi dengan system hidroponik. Budidaya hidroponik dapat 
diusahakan sepanjang tahun. Oleh karena itu harga jualnya tidak akan jatuh. Pemeliharaannya lebih muda karena tempat budidayanya relatif bersih, media tanamnya steril, tanaman terlindungi dari terpaan hujan, serangan hama dan penyakit relatif kecil, serta tanaman lebih sehat dan produkstivitas lebih tinggi [2].

Hidroponik berkembang karena banyak kelebihan yaitu: tanpa menggunakan tanah, air tetap berada dalam system dan dapat dipergunakan kembali, tingkatan nutrient dapat diatur sesuai kebutuhan tanaman, tidak menyebabkan polusi nutrisi dalam system lingkungan, berdaya hasil tinggi, dan penyakit serta hama dapat dengan mudah untuk ditanggulangi [3]. Sampai saat ini tanaman yang paling sering dibudidayakan dengan system hidroponik adalah tanaman sayuran daun salah satunya adalah pakcoy. Tanaman pakcoy (Brassica rapa L) merupakan salah satu tanaman yang mudah ditanam dan ekonomis. Tanaman ini dapat tumbuh di dataran tinggi dan dataran rendah [4].

Hidroponik merupakan solusi di bidang pertanian dengan menggunakan teknologi sederhana untuk memudahkan masyarakat dalam bercocok tanam.
Hidroponik mampu menghasilkan produksi tanaman yang lebih terjamin kebebasannya dari hama penyakit yang berasal dari tanah, dapat dijadikan profesi baru sebagai mata pencaharian bagi petani dan masyarakat yang tidak memiliki pekerjaan, meningkatkan pemenuhan sumber gizi keluarga dan masyarakat, dan apabila diusahakan dalam skala besar dapat meningkatkan ekspor produksi hortikultura segar dan berkualitas tinggi sehingga dapat menambah devisa negara.

Hidroponik juga memiliki keuntungan bagi lingkungan sosial karena dapat dijadikan sarana pendidikan dan pelatihan di bidang pertanian modern mulai dari kanakkanak sampai dengan orang tua, memperindah lingkungan dengan kesan pertanian yang bersih dan sehat dan usaha agribisnis di pedesaan tanpa mencemari lingkungan [5].

Tumbuhan yang dibudidaya secara hidroponik tumbuh dua kali lebih cepat dibandingkan dengan sistem konvensional. Hal ini disebabkan kontak langsung antara akar dengan oksigen, tingkat keasaman yang optimum, serta adanya peningkatan penyerapan nutrien dan nutrisi yang seimbang [6]. 
Adapun yang akan dijadikan sebagai mitra dalam kegiatan Pengabdian kepada Masyarakat adalah warga desa, persatuan petani, dan ibuibu pkk di desa taba padang rejang kecamatan hulu palik kabupaten bengkulu utara. Sebagian besar masyarakat desa taba padang rejang adalah para petani.

Oleh sebab itu, dengan adanya program Pengabdian kepada Masyarakat Universitas Muhammadiyah Bengkulu, pengabdi ingin melaksanakan kegiatan ini desa taba padang rejang kecamatan hulu palik kabupaten bengkulu utara. Sehingga menambah perekonomian masyarakat dan juga menghasilkan sayuran segar untuk komsumsi dalam rumah tangga.

\section{METODE PELAKSANAAN}

\section{Metode Pelaksanaan}

Metode yang dilaksanakan untuk mencapai tujuan adalah: 1) Penyuluhan untuk meningkatkan pengetahuan tentang hidroponik dengan seminar penyuluhan tentang sistem hidroponik modern untuk memberikan informasi kepada masyarakat dan memperlihatkan bahwa sistem yang akan dibuat dapat dilakukan dengan mudah. 2) Mendemontrasikan cara membudidayakan tanaman sayur dengan memperkenalkan kepada masyarakat alat dan bahan yang digunakan. Teknik budidaya yang dilakukan dari mulai persemaian sampai cara panen. 3) Pemberian bantuan dari benih sampai alat-alat yang digunakan dan bahanbahan yang dibutuhkan dalam proses budidaya sayur dengan sistem hidroponik modern agar pengetahuan yang sudah disosialisasikan dapat dilaksanakan. 4) Pendampingan selama proses budidaya sayur sampai panen. Hal ini ditujukan agar masyarakat benar-benar merasakan manfaat dari kegiatan Pengabdian kepada Masyarakat ini, dan dapat merasakan bahwa kegiatan Pengabdian kepada Masyarakat ini tidak bersifat insidentil saja, kapanpun mereka perlu bantuan pengetahuan, maka pengabdi akan menanggapinya.

\section{Konsep}

Konsep Hidroponik merupakan sistem budidaya pertanian yang dilakukan secara vertikal atau bertingkat, baik dalam ruangan maupun diluar ruangan dengan media utama air [7]. Sistem budidaya pertanian secara hidroponik ini merupakan konsep penghijauan yang cocok untuk daerah perkotaan dan lahan terbatas [8]. Dilihat 
dari sisi ekonomi, menanam sayuran dengan konsep Hidroponik sangat menguntungkan. Tanpa membutuhkan biaya yang tinggi dan dengan perawatan yang relatif mudah, warga bisa memenuhi kebutuhan sayur mayur sehat tanpa harus membeli [9].

Kegiatan pengabdian kepada masyarakat ini dilaksanakan di desa taba padang rejang kecamatan hulu palik kabupaten Bengkulu Utara. Adapun langkah-langkah yang dilakukan adalah sebagai berikut:

\section{Tahap Penyuluhan}

Mengkaji

Kebutuhan

Masyarakat. Pada tahap mengkaji kebutuhan masyarakat, Tim PKM (Pengabdian Kepada Masyarakat), kepala desa dan mitra melakukan kajian terkait kebutuhan masyarakat terhadap pelaksanaan pemberdayaan masyarakat melalui tanam secara hidroponik ini. Dan juga pengabdi sekaligus meminta ijin pelaksanaan kapan akan dilaksanakan dan mengondisikan tempat kegiatan.

\section{Menyusun Perencanaan}

\section{a.Menetapkan Tujuan}

Dalam menetapkan tujuan, pengabdi menyampaikan tujuan yang akan dicapai dalam kegiatan pengabdian kepada masyarakat. Sehingga dalam pelaksanaan pengabdian kepada masyarakat terstruktur dan terarah tentang tujuan yang akan dicapai. Pengabdi meminta kerjasama yang baik kepada kepala desa dan mitra-mitra yang dijadikan sasaran.

b. Penentuan Sasaran

Sasaran dalam pelaksanaan kegiatan pengabdian kepada masyarakat ini ialah warga gampong paya bujok teungoh dengan dua mitra yaitu: warga,persatuan petani dan Ibu-ibu PKK Desa Taba Padang Rejang.

\section{c. Menyusun Materi}

Dalam tahap ini, pengabdi menyiapkan materi dan menyusun secara spesifik dari setiap kegiatan awal sampai pada kegiatan penutup. Pengabdia menyiapkan materi tentang bagaimana hidrponik itu, bagaimana pembuatan tanaman hidroponik, bagaimana media yang digunakan dan sampai pada pelaksanaan kegiatan praktek cara bercocok tanam dengan menggunakan system hidroponik.

d. Mempersiapkan Alat-alat

Dalam tahap ini, pengabdi dan anggota pengabdian kepada masyarakat mempersiapkan alat-alat dan bahan yang akan dipraktekkan langsung di depan mitra. Adapun alat yang digunakan untuk bercocok tanam 
hidroponik dan bahan-bahan yang dibutuhkan adalah sebagai berikut:

1) Benih Tanaman

2) Netpot (wadah untuk tanaman)

3) Rockwool (media tanam yang bersifat menyerap dan menyimpan air

4) Sumbu (digunakan pada beberapa jenis sistem)

5) nutrisi(biasanya menggunakan Abmix untuk sayuran maupun buah- buahan)

\section{Cara bercocok Tanam}

Alat-alat yang dibutuhkan :

1) Rangka Tanaman (kami menggunakan system NFT, dengan rangka yang terbuat dari paralon disusun meningkat)

2) Wadah penampungan Nutrisi (bisa menggunakan drum air ataupun bak air)

3) Mesin air (bisa menggunakan mesin aquarium atau yang lainnya)

4) Nutrient Film Technique (NFT)

Pada sistem ini kontruksi dari bangunan tempat tanaman di buat bertingkat dengan lapisan air yang bisa diatur sendiri. Sistem kerja dari NFT ini ialah, air yang sudah bercampur dengan nutrisi dipompa kebagian pipa yang paling atas hingga mengalir turun kepipa paling bawah hingga kembali lagi kedalam bak penampungan dan hal ini dilakukan secara terus menerus. Kebanyakan dari sistem hidroponik menggunakan pompa untuk mengalirkan nutrisi kepada tanaman dimana pompa tersebut memerlukan listrik, Begitu pula dengan sistem NFT ini. Namun sistem NFT ini berbeda dengan sistem yang lainya dikarenakan ketika listrik yang digunakan untuk menghidupkan pompa mati, nutrisi yang dibutuhkan oleh tanaman masih tersisa didalam sistem perairan.

Sistem ini banyak disukai karena hanya akar tanaman saja yang menyentuh nutrisi sehingga tumbuhan lebih banyak mendapatkan oksigen dan hal ini menyebabkan tumbuhan lebih cepat berkembang.

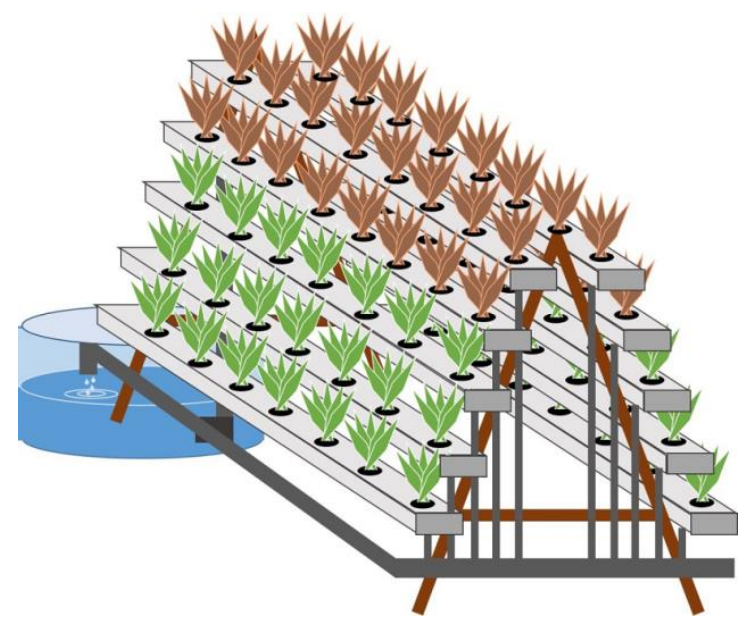

Gambar 1. Contoh System NFT

\section{Bahan-bahan yang dibutuhkan :}

1) Benih tanaman (buah-buahan atau sayuran. Contoh buah- 
buahan yaitu stoberi, tomat, paprika. Contoh sayuran yaitu pakcoy, kangkung, bayam dan selada)

2) Netpot (wadah untuk tanaman)

3) Rockwool (media tanam yang bersifat menyerap dan menyimpan air)

4) Nutrisi (biasanya menggunakan nutrisi $\mathrm{AB}$ MIX untuk buahbuahan maupun sayuran)

5) Trey (wadah untuk proses pembibitan)

\section{Penyemaian}

Penyemaian merukapan tahap awal dalam berkebun hidroponik, media yang digunakan yaitu rockwool. Cara menyemai yaitu sebagai berikut :

1) Media tanam rockwool dipotong kecil, diletakkan di atas wadah, dan dibasahi dengan air secukupnya agar basah

2) Pada rockwool dibuat lubang dengan menggunakan tusuk gigi untuk tempat bibit

3) Bibit tanaman dimasukkan ke dalam lubang dan wadah disimpan di dalam tempat gelap; Untuk tanaman yang menjulang tinggi seperti sawi, bayam dan kangkung, 1 rockwool bisa diisi 2-3 benih, tetapi untuk yang tumbuh kesamping seperti pakchoy dan selada cukup 1 benih saja. Untuk cabe dan tomat cukup 1-2 benih. Kelembaban rockwool harus diperiksa secara berkala. Apabila kering, maka perlu ditambahkan air.

4) Setelah 1-4 hari, bibit akan pecah yang ditandai dengan warna putih. Lamanya pecah tergantung dari jenis tanaman

5) Jika benih tanaman sudah pecah, maka wadah ditempatkan di daerah yang terkena sinar matahari minimal 6 jam sehari

6) Setelah berdaun empat, tanaman dipindahkan ke instalasi hidroponik yang telah diberi nutrisi sesuai dengan konsentrasi yang dibutuhkan tanaman.

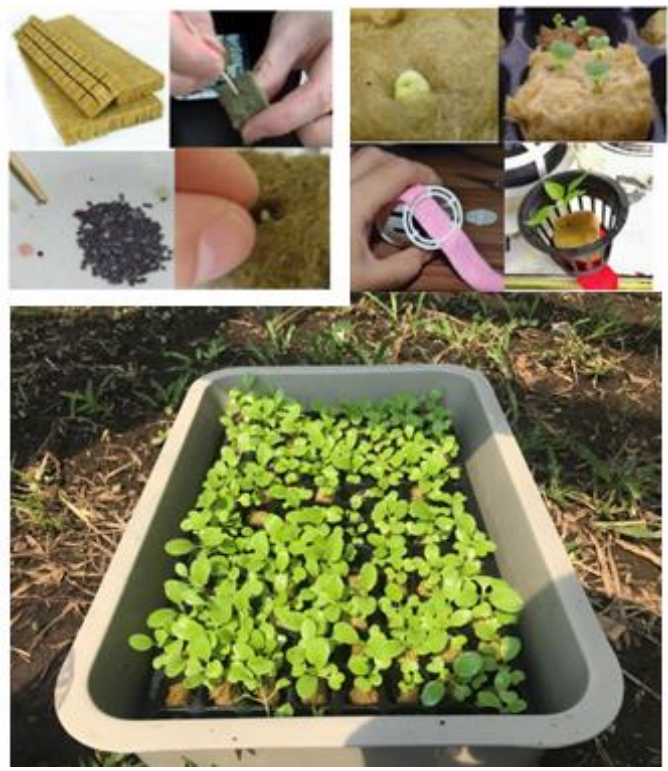

Gambar 2. Tahapan Pembibitan 


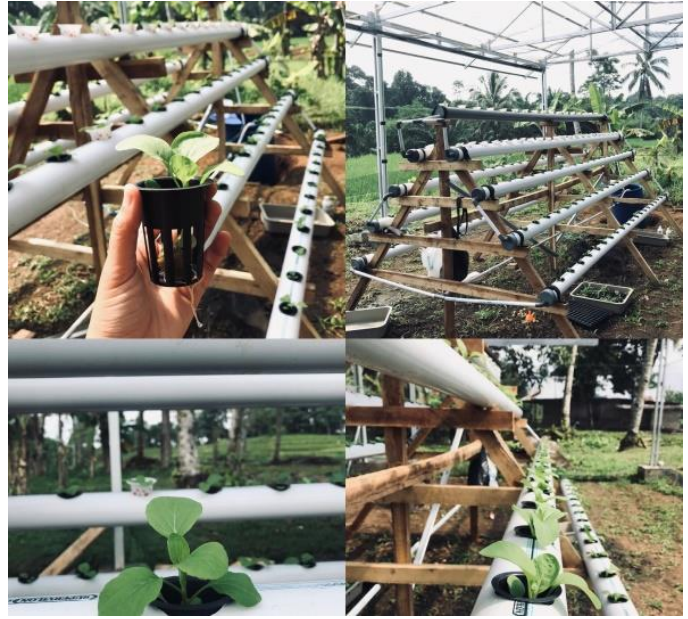

Gambar 3. Proses Pemindahan Benih

Ke Instalasi Hidroponik System NFT

\section{Penyiapan Nutrisi}

Pada dasarnya kultur air merupakan sistem tertutup ("closed system") di mana akar tanaman terekspos larutan nutrisi tanpa media tanaman dan larutan disirkulasi [10].

Nutrisi yang biasanya digunakan yaitu nutrisi AB MIX (gambar 4) Selain itu, alat-alat yang dibutuhkan yaitu botol bekas air mineral, gelas ukur, TDS meter (gambar 5) dan sendok pengaduk. Sebaiknya pada botol bekas diberi label nutrisi A dan nutrisi B. nutrisi kemasan kecil digunakan untuk membuat stok nutrisi sebanyak masing-masing $500 \mathrm{ml}$. nutrisi A dimasukkan ke dalam gelas ukur, kemudian ditambahkan dengan air sampai $500 \mathrm{ml}$, kemudian diaduk sampai larut. nutrisi A dimasukkan ke dalam botol berlabel A. Cara yang sama dilakukan untuk nutrisi B.

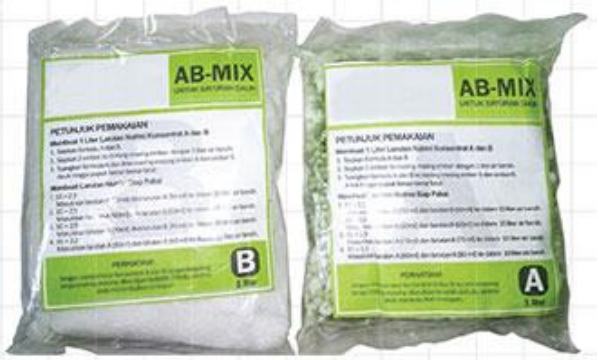

Gambar 4. Contoh Nutrisi AB MIX

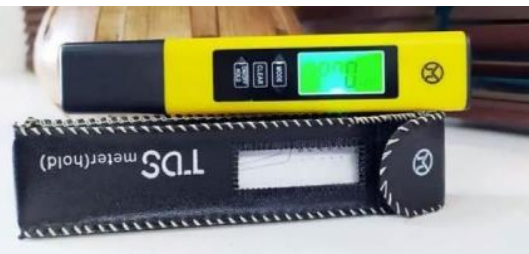

Gambar 5. TDS Meter

Masing-masing konsentrat pupuk ini dapat digunakan sebagai stok. Untuk membuat larutan pupuk sebagai nutrisi tanaman maka digunakan perbandingan $5 \mathrm{ml}$ pupuk $\mathrm{A}+5 \mathrm{ml}$ pupuk $\mathrm{B}+1$ liter air. Untuk pemakaian dalam jumlah yang banyak, $50 \mathrm{ml}$ pupuk $\mathrm{A}+50 \mathrm{ml}$ pupuk $\mathrm{B}+8 \mathrm{~L}$ air, akan menghasilkan konsentrasi pupuk sekitar 1400 ppm. Kebutuhan masing-masing tumbuhan berbeda. Konsentrasi nutrisi untuk jenisjenis tanaman dapat dilihat pada gambar 6. Masa panen tanaman dapat dilihat pada gambar 7, dan kualitas hasil panen dapat dilihat pada gambar 8 . 


\begin{tabular}{|c|c|c|}
\hline NAMA SAYURAN & pH & PPM \\
\hline LOBAK & $6.0-7.0$ & $840-1540$ \\
\hline SELADA & $6.0-7.0$ & $560-840$ \\
\hline CAULIFLOWER & $6.5-7.0$ & $1050-1400$ \\
\hline PAK CHOI & 7 & $1050-1400$ \\
\hline KETIMUN & 5.5 & $1190-1750$ \\
\hline EGGPLANT & 6 & $1750-2450$ \\
\hline TOMAT & $6.0-6.5$ & $1400-3500$ \\
\hline SAWI PAHIT & $6.0-6.5$ & $840-1680$ \\
\hline STRAWBERRY & 6 & $1260-1540$ \\
\hline KANGKUNG & $5.5-6.5$ & $1050-1400$ \\
\hline SAWI & $5.5-6.5$ & $1050-1400$ \\
\hline KAILAN & $5.5-6.5$ & $1050-1400$ \\
\hline BAYAM & $6.0-7.0$ & $1260-1610$ \\
\hline BAWANG PUTIH & 6.0 & $980-1260$ \\
\hline SELEDRI & 6.5 & $1260-1680$ \\
\hline CABE & $6.0-6.5$ & $1260-1540$ \\
\hline WORTEL & 6.3 & $1120-1400$ \\
\hline marjoram & 6 & $1120-1400$ \\
\hline Peterseli & $5.5-6,0$ & $560-1260$ \\
\hline Peas & $6.0-7.0$ & $980-1260$ \\
\hline Jagung manis & 6 & $840-1680$ \\
\hline Kentang & $5.0-6.0$ & $1400-1750$ \\
\hline Mawar & $5.5-7.5$ & $800-1050-1750$ \\
\hline & & \\
\hline Gamb & & \\
\hline & & \\
\hline & & 5111 \\
\hline
\end{tabular}

Gambar 6. Kosentrasi Nutrisi

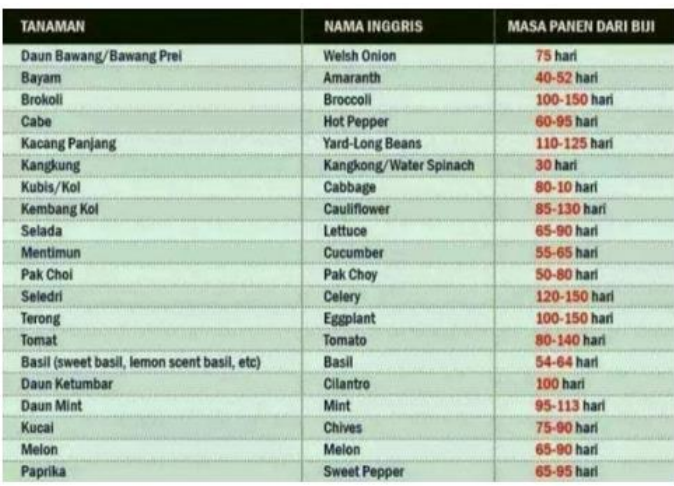

Gambar 7. Masa Panen Tanaman

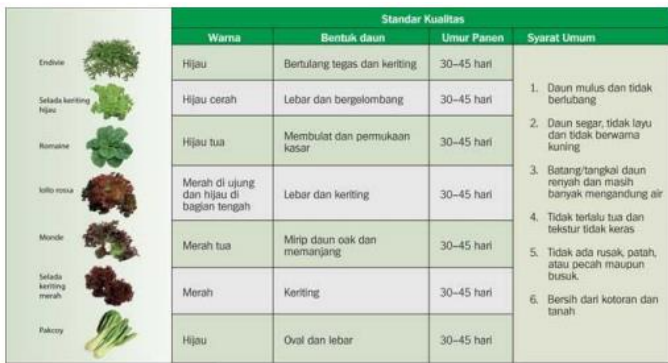

Gambar 8. Standar Kualitas Tanaman

\section{HASIL DAN PEMBAHASAN}

\section{Tahap Demonstrasi}

Pada pertemuan pertama, kegiatan dibuka oleh moderator dan pembukaan pelaksanaan kegiatan pengabdian kepada masyarakat yang dibuka oleh ketua tim dan memberikan kata sambutan dan pengarahan tentang pelaksanaan kegiatan pengabdian kepada masayarakat ini. Dan kemudian disusul oleh kata sambutan oleh kepala desa dalam rangka pembukaan pelaksanaan kegiatan pengabdian kepada masayarakat tentang hidroponik.

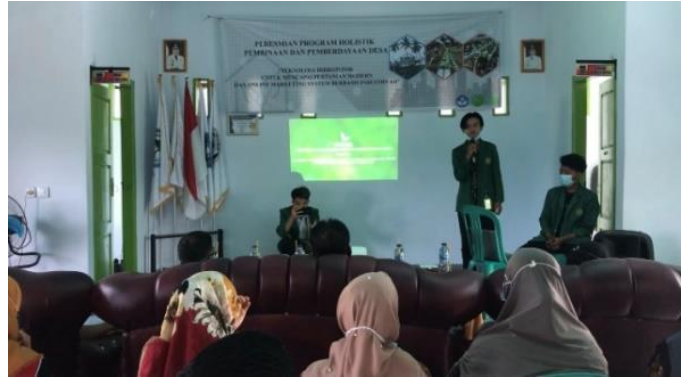

Gambar 4. Demonstrasi program

Gambar 9. Penyerahan Hasil Program Hidroponik

Pada tahap ini, ketua tim pengabdian kepada masyarakat menyerahkan paket hidroponik kepada kepala desa dan mitra desa untuk melanjutkan kegiatan ini selain menjadi desa percontohan hidroponik, tempat edukasi hidroponik, agromart dan ini juga kedepanya akan bisa menjadi agrowisata didesa tersebut 


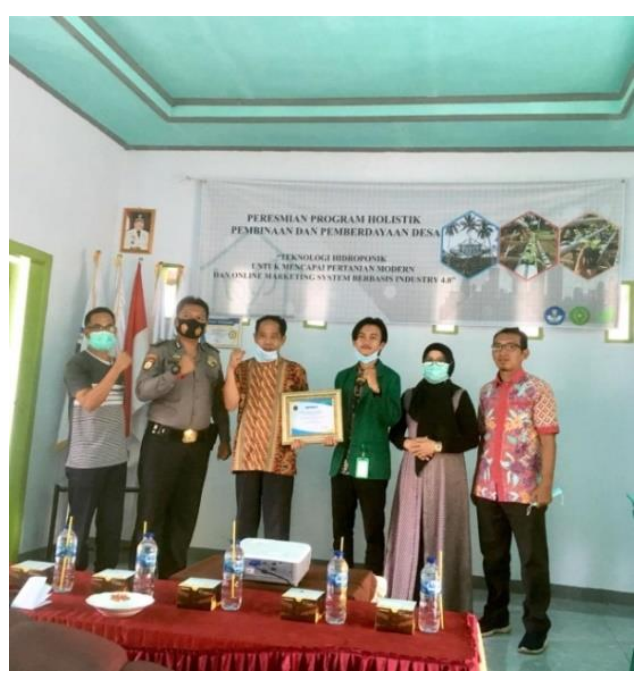

Gambar 10. Penyerahan Piagam

\section{Tahap sosialisasi}

Pada tahap ini, pengabdi melakukan sosialisasi dalam cara pembibitan penyemaiaan terhadap tanaman hidroponik.

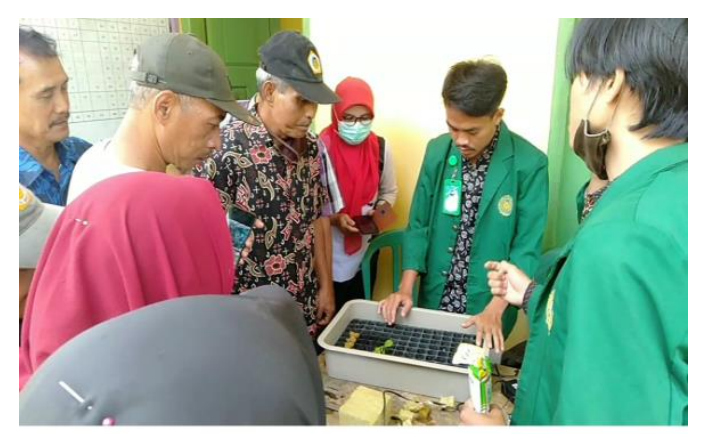

Gambar 11. Sosialisasi

\section{Tahap Pendampingan}

Pada tahap ini, Tim pengabdian kepada masyarakat melakukan pendampingan ke masyarakat desa taba padang rejang dalam rangka melihat langsung bagaimana cara memelihara tanaman hidroponik.

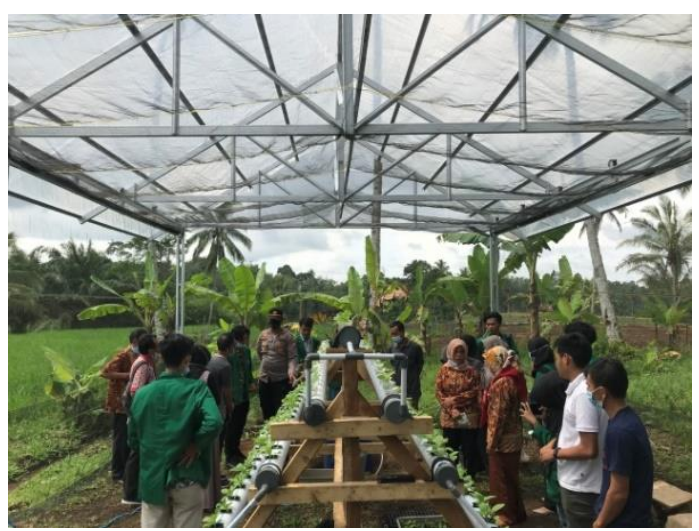

Gambar 12. Pendampingan

\section{Tahap Peresmian Desa Hidroponik}

Pada tahap ini, peresmian dilakukan dengan memotong pita sebagai simbolis terhadap program yang sudah dilaksanakan bersama Kades, Kapolsek, BPP (Balai Penyuluhan Pertanian) serta kelompok masyarat yang ada di Desa Taba Padang Rejang.

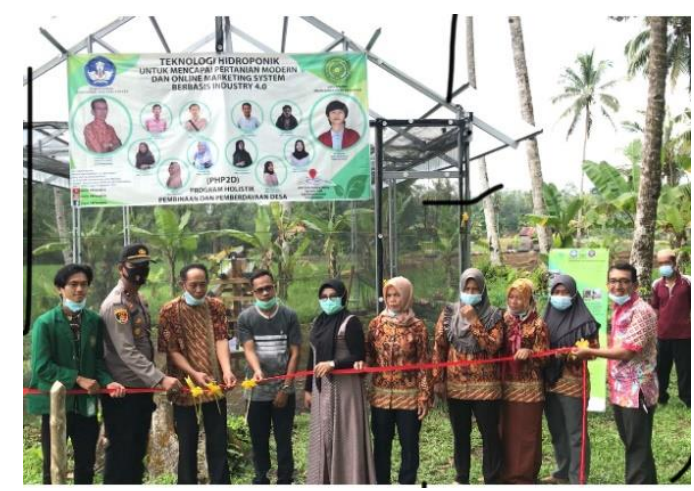

Gambar 13. Peresmian Bersama Para Tokoh Masyarakat 


\section{Tahapan Perkembangan Pakcoy}

Berikut ini adalah penampakan perkembangan pertumbuhan sayuran pakcoy hasil dengan system teknologi hidroponik bisa dilihat dari foto :

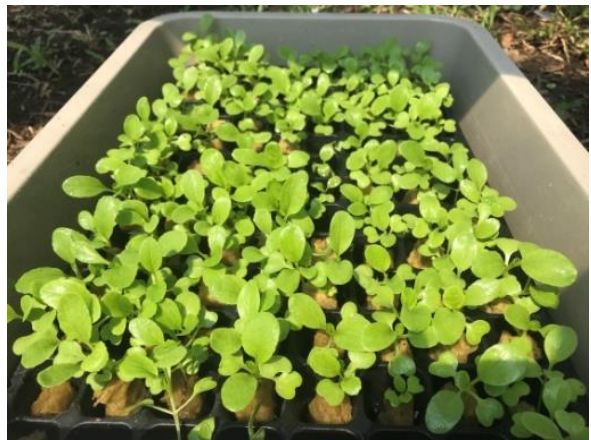

Gambar 14. Pakcoy Umur 12 hari

Perkembangan sayuran pakcoy umur 12 hari yang masih ditempatkan pada media rockwool.

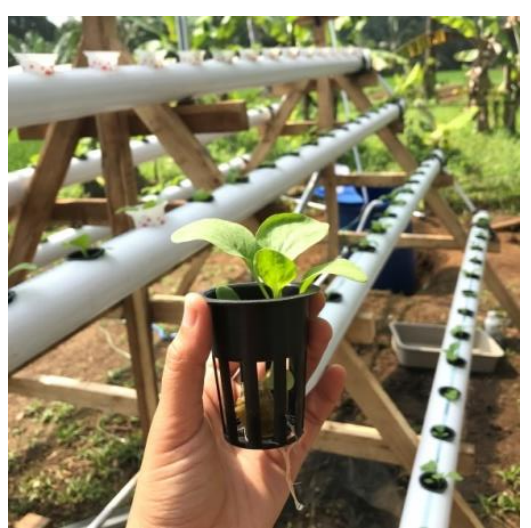

Gambar 15. Pakcoy Umur 20 hari

Gambar 15 ini melihatkan perkembangan sayuran pakcoy pada umur 20 hari, dan pada ukuran atau umur ini sayuran pakcoy sudah siap dipindahkan kemedia hidroponik (greenhouse).

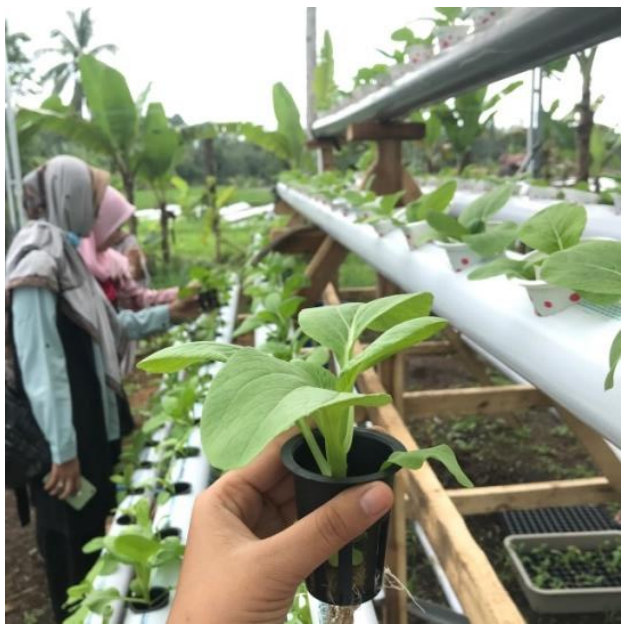

Gambar 16. Pakcoy Umur 25 hari

Pada gambar 16 ini memperlihatkan pertumbuhan sayuran yang bagus dan cukup nutrisi, dapat dilihat dari perbedaan pertumbuhan ukuran pada umur 20 hari dengan warna yang hijau segar. Apabila tanaman pakcoy ini kurang nutrisi, maka tanaman tersebut akan terlambat proses pertumbuhannya dan warnanya terlihat kekuningan.

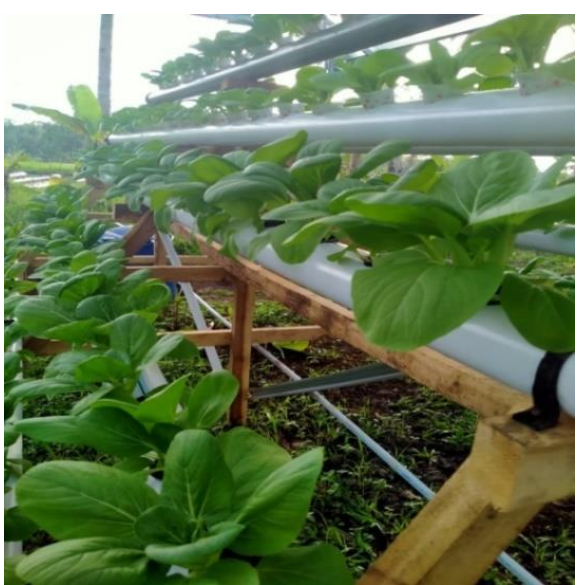


Gambar 17. Pakcoy Umur 30 hari

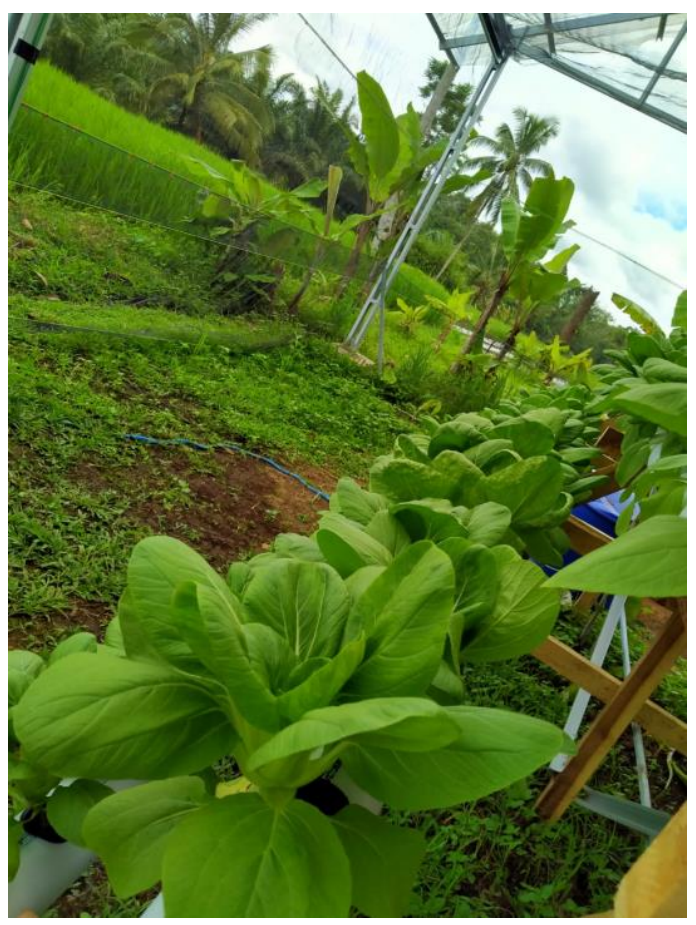

Gambar 18. Pakcoy Umur 32 hari

Pada gambar 17 dan 18 memperlihatkan umur tanaman pakcoy pada usia 30-32 hari, pada umur ini tanaman sudah dalam kondisi yang bagus untuk memanen, terlihat dari daun sawi dewasa berbentuk oval melebar, tangkai daunnya berwarna hijau cerah, bentuknya relative pendek jauh berbeda dengan sawi yang berukuran panjang.

\section{PENUTUP}

Kesimpulan

Berdasarkan dari Kegiatan pelatihan dan praktik pembuatan hidroponik yang telah dilaksanakan ini. Adapun hasil dari Tim Pengabdian Masyarakat ini adalah:

1. Warga masyarakat Desa Taba Padang Rejang memahami cara bertanam hidroponik serta mampu mempraktekkannya.

2. Hasil dari program ini terbentuk desa percontohan hidroponik, pusat edukasi hidroponik, agromart, dan menjadi desa agrowisata sesuai dengan program kerja yang dicanangkan Kepala Desa Taba Padang Rejang Kecamatan Hulu Palik Kabupaten Bengkulu Utara.

\section{DAFTAR PUSTAKA}

1. Lonardy, M. V. (2006). Respons tanaman tomat (Lycopersicon esculentum mill.) terhadap suplai senyawa nitrogen dari sumber berbeda pada sistem hidroponik. Skripsi"'(Tidak

Dipublikasikan). Universitas Tadulako, Palu.

2. Junia, L. S. (2017). Uji Pertumbuhan Dan Hasil Tanaman Pakcoy (Brassica Rapa L.) Dengan Pemberian Pupuk Organik Cair Pada System Hidroponik. Agrifor, 16(1), 65-74.

3. Sastro, Y., Astuti, E. P., Sutardi, S., \& Rokhmah, N. A. (2015). Efektivitas Kultur Campuran Bakteri Penambat N-Bebas dan Pelarut Fosfat Pada Jagung Manis. In Prosiding Seminar Nasional Pengembangan Teknologi 
Pertanian.

4. Megsari, R., \& Asmuliani, R. (2020). Uji Pertumbuhan Tanaman Pakcoy (Brassica rappa L) Dengan Pemberian Nutrisi AbMix Dan Pupuk Organik Cair Pada System Hidroponik. Musamus Journal of Agrotechnology Research,2(2), 45-51.

5. Mugundhan, R. M., Soundaria, M., Maheswari, V., Santhakumari, P., \& Gopal, V. (2011).

Hydroponics"-a novel alternative for geoponic cultivation of medicinal plants and food crops. International Journal of Pharma and Bio Sciences, 2(2).

6. Wahome, P. K., Oseni, T. O., Masarirambi, M. T., \& Shongwe, V. D. (2011). Effects of different hydroponics systems and growing media on the vegetative growth, yield and cut flower quality of gypsophila (Gypsophila paniculata L.). World Journal of Agricultural Sciences, 7(6), 692698.

7. Mas' ud, H. (2009). Sistem hidroponik dengan nutrisi dan media tanam berbeda terhadap pertumbuhan dan hasil selada. Media Litbang Sulteng, 2(2).

8. Turner, T. (2005). Garden history: Philosophy and design 2000 BC2000 AD. Routledge.

9. Tallei, T. E., Rumengan, I. F., \& Adam, A. A. (2017). Hidroponik untuk pemula. Manado: LPPM Unsrat.

10. Rosliani, R., \& Sumarni, N. (2005). Budidaya tanaman sayuran dengan sistem hidroponik. 